\title{
Digital transformation and its impact on our digital wellbeing
}

\author{
Kathryn MacCallum \\ Kathryn.maccallum@canterbury.ac.nz \\ University of Canterbury, Christchurch, New Zealand \\ Keywords: Digital Wellbeing, Digital Transformation, Technology Enhanced Learning
}

\section{Abstract}

The pandemic has transformed how we engage with digital technologies. Technology is now used to support all facets of our daily lives, including work, learning, and enjoyment (Schleicher, 2020). While the pandemic may have accelerated our adoption, this upward trend has been happening for many years, and we are no longer in a world where the digital, virtual or online can be viewed as separate from our everyday life (Myers, Erikson \& Small 2013). The effects of digitalisation have been felt at all levels, including education. As educators we can be optimistic, pessimistic or pragmatic about many of these changes, but they cannot be ignored (Gluckman \& Allen, 2018).

The influence of digital transformation has highlighted the critical need to better manage our students' and our wellbeing. Wellbeing, as a concept has been challenging to define due to its complex and multi-faceted nature. More recent approaches have shifted towards ideas around the quality of life and the notion of flourishing in the positive psychology movement (Dodge et al 2012). In an endeavour to explain wellbeing which moves from the binary positive versus negative wellbeing, Dodge et al (2012), proposed that wellbeing is "the balance point between an individual's resource pool and the challenges faced" (p. 230). In other words, people's wellbeing can be positively influenced if they are given the resources to address and overcome the adversities they face. Using their balance metaphor, a person's feeling of wellbeing can be stabilized when they feel that they have the psychological, social and physical resources and skills necessary to meet a particular psychological, social and/or physical challenge. This approach, therefore, acknowledges the see-saw effect of wellbeing but also that individuals have agency over their wellbeing.

So, what does this mean for student wellbeing in the context of learning technologies? As highlighted by Gluckman and Allen, (2018) "to understand wellbeing in the 21st century requires an understanding of transformative digital technologies as drivers of change not just in human material circumstances, but also in human values and organisational systems that support wellbeing." (p. 10). Therefore, when considering digital wellbeing we need to acknowledge the transformative power of digital technology to drive both positive and negative outcomes and ask how we can tip the balance by leveraging the positives of this transformation.

The presentation will explore the challenges that digital transformation brings to education and how as educators we can tip the balance to leverage technology to support our student's and our digital wellbeing. The presentation will also focus on ways as educators we can use learning technologies to support students with the resources and skills to enhance their digital wellbeing.

\section{References}

Dodge, R., Daly, A. P., Huyton, J., \& Sanders, L. D. (2012). The challenge of defining wellbeing. International Journal of Wellbeing, 2(3). https://www.internationaljournalofwellbeing.org/index.php/ijow/article/view/89

Gluckman, S. P., \& Allen, K. (2018). Understanding wellbeing in the context of rapid digital and associated transformations. The International Network for Government Science Advice. https://www.ingsa.org/wpcontent/uploads/2018/10/INGSA-Digital-Wellbeing-Sept18.pdf

Meyers, E. M., Erickson, I., \& Small, R. V. (2013). Digital literacy and informal learning environments: an introduction. Learning, Media and Technology, 38(4), 355-367. 
SoTEL Symposium 16-18 February 2022

https://doi.org/10.1080/17439884.2013.783597

Schleicher, A. (2020). The impact of COVID-19 on education: insights from Education at a Glance 2020. Paris: OECD. https://www.oecd.org/education/the-impact-of-covid-19-on-education-insights-education-at-a-glance2020.pdf 